\title{
E-Karaoke Learning for Gender Empowerment in Rural India
}

\author{
Payal Arora \\ Teachers College, Columbia University \\ Pa2177@columbia.edu
}

\begin{abstract}
A folksongs karaoke product has been created to increase usage of subtitled media to enhance literacy and technology use, particularly among girls in rural India. This entails generating and proliferating popular local folksongs with social and cultural themes of interest to girls, accompanied by the award-winning Same Language Subtitling (SLS) feature. In this paper, the prime goal is to discuss possible implications of this novel technology content on girls' socialization, education, and activism. Based on initial findings from a pilot test of this product in schools, private and public in rural India, I propose that this product has the potential to raise literacy among girls through musical enculturation and entertainment in rural India. By linking folksongs to computers, I argue that this association can shape, transform and/or (re)configure spaces for/by girls in rural India through interaction with technology in ways meaningful to them. Thereby, I problematize the transposition of "western" perspectives of gender and technology onto the rural terrain as understood within a development discourse.
\end{abstract}

Key words: gender, technology, karaoke, folksongs, literacy, rural India

\section{INTRODUCTION}

Jenson, Castell, \& Bryson (2003) draws a distinction between "equity" and "equality" in guiding the understanding of gender and technology. Particularly the notion of gender "equity" practices as that constructed within a framework of "equality." Equality in practice, they suggest, connotes equal access to resources, that being the same quality of opportunity and experience undifferentiated by sex. Equity on the other hand implies that what is fair is not necessarily equal, and further, that "removing barriers to access for girls does not address inequitable treatment once they are given access, nor does it establish a means of restructuring the existing school culture" (p. 562). In other words, configuring new equitable spaces for girls involves not just the facilitation of access to technologies but also an alteration in approaches and mindsets that allows for the maximizing of these new spaces in ways meaningful to them. Further, Cockburn (1992) proposes that girls have been actively resisting high end technologies because it threatens their feminine identity. This identity, the author argues, poses as a self-regulating mechanism in women's thoughts and actions. This is viewed as a problem as girls appear to not to be interested in entering into the traditionally male domain including the IT industry, and they do not in fact do so, despite twenty years of equity theory and at least a decade of equity policy (Bernstein, 2000; Gehring,
2001). Similarly, Schrum \& Bracey states that the gender divide in technology is in fact an extension to the gender divide in society (Solomon, Allen, \& Resta, 2003). They espouse that much of educational content, online and offline favor the representation of the male domain and act as barriers to access and usage of technology by women and girls. Besides, Wajcman (1991) emphasizes that access to technologies is not just access to the physical medium per say but rather to opportunities in domains that are male and protected. The author argues that through the systematic and historical exclusion of women from skilled jobs and training in the technological field, current female antipathy towards technology has transpired. Further, Harris (1999) points out that there are fewer females than males in the media be it music videos, news programs, cartoons, and the like. He states that women tend to be portrayed in traditionally stereotypical environments doing conventional home cooking tasks and are disproportionately seen as home makers and mothers. In other words, gender inequity in technology is often treated as a symptom of lack of access rather than a systemic failure of inequity in technological processes including in the creation, distribution and implementation of technological content. Thereby, to achieve gender equity within the technological realm, it is suggested that women need to become (co) producers of their own knowledge and perspectives to make sure they are adequately and appropriately reflected in these new technological spaces.

While I agree in the making of the distinction between equality and equity as Jenson, Castell and Bryson have outlined for us, we have to be cognizant of the fact that the divide is not necessarily between the sexes but rather, can exist within the female terrain. In other words, "women" and "girls" are not monolithic entities in a constant state of consensus. In fact, it is misleading to uncritically transpose "First World" feminism to frame our understanding of technology access and usage by girls over "Third World" spaces. Here, what constitutes as "gender empowerment" is often perceived as a homogenous, non-conflicting zone between development "solutions" of girls' access and usage of technologies to girls' "problems," as in their resistance in mindsets to these technologies. Klenk (2004) argues this cogently in her investigation of women in rural Kumaon in North India where she challenges the construct of the "developed woman." She argues that contrary to the notion of subjugation amongst women in rural India, women generate new and culturallyspecific negotiation strategies to serve their needs. She underlines that in doing so, women's concerns often go beyond commonly perceived gender issues, be it fertility, safety, child rearing, and marital status to that which is economic, political, 
technological, and environmental, be it local and/or global in nature. She compels us to reevaluate the circulation of commonly held perceptions and representations of women as we shape development solutions for this "marginalized" group. Thereby, rather than perceiving women and girls as actively resistant to new technologies as Cockburn (1992) would have us believe, they can instead be seen as dynamic agents to change and responsive entities to innovations within their communal and personal lives. Further, one can dispute the argument made by Harris (1999) implying that conventional representations of women and girls such as home making have disempowering effects among women and girls in rural India. On the contrary, as we will see below in the representation within folksongs, these images may serve as symbols of strength where women through "traditional" activities may navigate and center families and communities through their multifarious roles in society.

Klenk builds on Bhabha (1990), Escobar (1995) and Mohanty's (1991) pioneering discourse on the "Third World" wherein they accuse the construction of this all encompassing rubric as a convenient and efficient apparatus for exercising power with sweeping solutions across geopolitical, social and cultural spaces in the name of development. Thereby, within this development discourse, "women" often constitute as a category, a unit of victimhood and suffering, subject to powers and control from outside forces. Naturally then with this view, the idea that women could be active participants in constructing, negotiating and shaping spaces in their interaction with technologies for example would be negated or relegated to the background. Rahnema (1990) and Parpart (1995) similarly critique such perspectives in which the south often ignores womens' input even when there has been evidence of it being critical to the sustenance of the region. Also, when efforts are made to involve local women in development projects, in practice women are sidelined to the periphery. Here, Parpart comments, local experts' agendas overtake that of the women for whom these projects are often construed for. Participation then as Rahnema points out, often reifies into the experts search for ways of convincing the "uneducated" of their own educated views and approaches.

Perhaps exemplifying the phenomenon of fractured gender perspectives in this case study is in my own experience in Kuppam with my coworker, Jayamma, and her family. I had been invited to dinner to her house, a simple one room home in a rural village, an hour from Kuppam town. Her husband was volunteering with a health non-governmental organization (NGO) with a hope of getting a job with them soon. He had been unemployed for two years now. Jayamma had been supporting him and their eight year old son by working as a teacher and now, as a local coordinator for our project. While dinner was being served, Jayamma was eager to share with me her husband's work of teaching the community about HIV/AIDS. With little warning, she pulled out the health kit her husband used in his rounds. Then husband and wife did a little demonstration for me on how they went about explaining to the people the usage of condoms. As I sat there watching them take out a plastic penile apparatus and act out their speech to the villagers, I realized that I was the only one facing any embarrassment. Although I had been living in Kuppam for the last six months, I was undergoing a constant evaluation of my perspectives of what constituted as the "rural woman". In spite of having been brought up in India, I recognized that I had simplified the rural woman into a predictable "other". Over the months however, these neat boundaries were dismantled, transplanted with a complex web of identities for the "rural woman" that to date cannot be adequately and authoritatively described.

Parpart would place this struggle under current development trends that attempt to build on local knowledge yet intersect with western and modernist frameworks, problematizing the relationship between indigenous knowledge brokers and western and western-trained development specialists like myself. Given this daunting task, she recommends to listen to the needs of those we seek to serve:

Truly listening to others entails moving outside your own conceptual frameworks, especially the binary thought structures and patriarchal character of most Western knowledge. It requires the recognition that differences, and different voices, cannot just be heard, that language is powerful and that subjectivity (voices) are constructed and embedded in the complex experiential and discursive environments of daily life. (1995, pp. 239)

In this spirit, we attempted to co-produce multimedia content that would meaningfully engage and entertain girls in Kuppam, India. By no means do we assume that these girls do not have other means of empowering themselves and negotiating spaces that are critical to their needs and concerns. We hope however, that this could be considered another space where they could engage in their interests and gain encouragement through the usage of new technologies with literacy as an incidental phenomenon. As we have seen at the start, much of the current literature on gender and technology is in fact rooted in western practices of girls' interaction with computers and the internet. In this paper, I hope to reveal some of the complexities in delving into technology usage and literacy practices in rural India with meaningful engagement at the forefront of our concerns.

\section{THE SLS FOLKSONGS PROJECT}

The SLS folksongs multimedia tool builds on the Same Language Subtitling (SLS) innovation that won the World Bank Development Marketplace award i in 2002, the 'Tech Laureate' honor ${ }^{\text {ii }}$ from the Technology Museum of Innovation in 2003 and the Google grant ${ }^{\mathrm{iii}}$ for 2005-2006. In essence, the SLS feature entails leveraging popular film-based entertainment programming on television with subtitles in the same language to enhance reading experiences among neoliterates. The subtitles change color to match the audio track exactly so that even a non-literate person is able to identify the word being sung at any given time. This concept was conceived in 1996 by Dr. Brij Kothari, founder of 
PlanetRead $^{\text {iv }}$, the non-profit agency executing this project and professor at the Indian Institute of Management in Ahmedabad, India (IIM-A). Almost ten years later, the enormous impact of this simple and low cost initiative on literacy has become a recognized phenomenon through cumulative empirical evidence over the years (Kothari, 2000; Kothari, Pandey, \& Chudgar, 2004; Kothari \& Takeda, 2000). The correlation of SLS with reading improvements among both males and females and audience preference of subtitled to unsubtitled songs has been established. (Kothari \& Takeda, 2000). Furthermore, the role of SLS in enhancing entertainment has been demonstrated with literacy being achieved subliminally (Kothari, 2000).

However, amidst this success emerged reservations on using film-based content, particularly within formal educational settings: The battle against 'filmi culture' on moral grounds has proven to be a major stumbling block for some policy makers (Kothari \& Takeda, 2000, p.137). In 2001, an agreement was made between Doordharshan, the national television station in India and IIM-A to try SLS on folksong programming recorded in-house. Results showed that even though film song programs gained higher viewership than folksong programs, the folksong lyrics became more widely used and displayed openly by people in schools and homes (Kothari, Pandey \& Chudgar, 2004). Further, this folksong project raised about $50 \%$ of the telecast and SLS expenses from advertising revenue. This positive outcome gave birth to the idea of using folk content with SLS for engagement and literacy among the rural populace. This tool using folksongs has been funded by Hewlett Packard (HP) as part of their inclusive community project ${ }^{\mathrm{v}}$ entailing the dissemination and usage of technologies for social and economic mobility in Kuppam, a rural constituency in Andhra Pradesh, South India.

This paper specifically looks at the ramifications this product may have on girls' literacy and technology usage through the digitalization and employment of folksongs. Due to the interdisciplinary nature of the subject at hand, reviewed literature has been woven within the discussion with the hope that it will lead to a more lucid understanding of the specific implications discussed. This paper will follow the format of describing the project and its pilot testing followed by results garnered through these initial efforts. This will lead to the discussion section on implications of the product for gender empowerment, concluding with recommendations and concerns for future research in this budding field of ICT content production and its relation and impact on gender in rural India.

The Making of the Product: Through Hewlett-Packard sponsorship, PlanetRead spearheaded the making of a prototype CD-ROM based jukebox of SLS folksongs in Kuppam, a rural constituency in Andhra Pradesh, South of India. This process was a constant struggle in negotiating the "local" with the "popular" in the shaping of content. Decisions on the length of folksongs, its themes, acoustics, and the like necessitated a balancing act between financial, human and cultural resources with a constant effort to allow for the local to dictate the nature of this product. The dilemma of authenticity though pervaded the process as the spectrum of what constituted as "authentic" variegated tremendously in themes, formats and styles, at times conflicting with one another and challenging our percepts of "folk" that we brought to this project (Arora, 2006a). With the pervasiveness of film songs enjoyed across villages in India, the line between cinema and folk content often blurred in determining engagement among girls in Kuppam. Although driven by a participatory approach to this diverse cultural scape, we were at times compelled to take on a reductionist stance when making decisions on features of the product, be it in our perception of what entailed a rural audience, gender issues to what constituted as "popular" within this domain (for further analysis of the process of production see Arora, 2006a). That said, with a goal for meaningful engagement, success in this project was primarily equated with the enjoyment of folksongs through subtitled media by the target audience, in this case high school girls in Kuppam constituency.

Rather than invent notions of what attributed to "gendered" folksongs, we conducted vast surveys on popular folksong preferences and worked closely with legitimate local cultural action groups, women groups (particularly self help groups- SHGs, see Arora, 2006a), and popular women folk artists in the cultivation of this content. The key songs surveyed as popular among girls and women were Parvati Tanaya (a religious song) Jum Jum Taraare ( a microfinance song for women by women), Kantaki Katukapetti ( a motherdaughter song) and Chandavalira (an educational song). Some are historically older songs such as the religious and motherdaughter song while the more recent songs pertain to topics of education, microfinance and the like. To reduce misinterpretation in the visualization of these songs, we adopted a literal transcription and representation approach of the lyrics line by line with visual stills drawn from the Kuppam surrounding. Further, we optimized female singers, both women and girls for many of these songs. Thereby, in triangulating surveys with involvement of community activists and women folk artists we were able to in part mitigate and perhaps circumvent some of these hurdles of (mis)representations of a community we were not intimately familiar with. It is important to concede that the prime intent was not to mirror in exactitude the local folksongs, but rather to harness the most popular songs to allow for engagement among girls within this community.

Product description: Photographic stills of the local village environment, were combined with Telugu folksong audio files and Telugu and Roman script subtitles, allowing participants to view and sing along with the songs. Popular folksongs performed by respected local singers were recorded professionally. Each song was picturized in the village context through a set of digital photos. These stills appear in tandem with the audio file, with the highlighting of the text of the lyrics at the bottom of the screen.

The Kuppam community: Located at the confluence of Karnataka, Tamil Nadu and Andhra Pradesh, Kuppam is strategically if not symbolically stationed amidst the three states. The constituency of former chief minister Chandrababu 
Naidu, Kuppam had the reputation of a prison encampment area as of ten years ago. Today Kuppam has been brandished by some as the 'silicon valley of the east' (Srinivasan, 2001, p. 3) where new technologies are being tried and tested within its vicinity. It is a rural Indian village, 105 kilometers from Bangalore on the Bangalore-Chennai railway. Telugu is the official and most widely spoken language in the state. Yet, given its proximity to the neighboring states and a sizable Muslim population, Tamil, Kannada, Urdu and Hindi are spoken too. With a population of around 300,000 people across 5 districts or mandals, the area has experienced a transformation in health, education, agriculture and employment services driven by a plethora of public and private sector schemes.

According to government data from the Kuppam Area Development Authority board (KADA, 2003), impressive strides have been made to advance and empower women and girls in Kuppam. For instance, cycles have been provided to all high school girls, particularly those from scheduled castes and tribes to allow for easier mobility to schools. This was in response to parental concerns for the safety of their girls in commuting to school, reported to be an important contributing factor in dropout rates of girls from secondary schooling. Further reforms included the establishment of a model residential school with the support of World Bank in 2003, targeting girls from the most marginalized castes and tribes. Also, women's microfinance groups reportedly increased from a total of 156 in 1994 to almost 3000 women's groups spread out across Kuppam in 2003. Interestingly, the Dravidian University, a public institute of higher learning was set up in 2003 to focus on South Indian folklore and culture. Additionally, educational statistics (see Table 1) indicate almost full enrollments among primary school children in the Kuppam community, 97.5\% in 2003 against $59 \%$ as of 1989. Among government high school children, about $90 \%$ belong to scheduled castes and tribes in contrast to $60 \%$ of high school students from private schools. The boys outnumber the girls in both private and public high schools: $57 \%$ in government and $62 \%$ in private high schools. Interestingly, only $26 \%$ of the teachers in government schools are female while around $76 \%$ of the teachers in private schools are women. Part of this is attributed to the lower salary received in private schools as well as the lack of mandatory rules regarding teacher certification amongst private schools.

Procedure: The pilot project was conducted across eleven high schools $(\mathrm{n}=405)$, five private and six public/government schools in Kuppam constituency (Table 1). English is the medium or co-medium of instruction for private high schools in this area while government high schools utilize Telugu, the regional language of instruction. We chose these schools within this area due to their access to computers as part of the Vidya Vahini Scheme, a government scheme implemented to target several disadvantaged government high schools by providing computers and other high end technologies to mitigate the digital divide in rural areas (for an analysis of computers in high schools in Kuppam, see Arora, 2006b).
We demonstrated this product in the computer labs of these select schools. The teacher was present for all demonstrations. The total number of students at a given time ranged from 15 to 40 , with a more balanced ratio of boys to girls in the government schools as compared to the private schools (Table 2). We spent about an hour per session, starting with viewing of the folk CD-ROM followed by a display of Telugu film songs, both with the same language subtitling feature. We used the film CD-ROM as a benchmark for engagement. The intent was not to prove that folk is better than cinema but that folksongs have strong appeal among rural children, particularly among girls. All sessions were conducted in Telugu. Questions of preference were asked of both boys and girls: subtitling versus non-subtitling, folk versus the cinema $\mathrm{CD}$, and within the folk $\mathrm{CD}$, preference for their favorite songs. Several sessions were videotaped. It is important to keep in mind that the film songs CD was of cinematic professional quality while the folksongs $C D$ was a low budget production utilizing visual stills instead of the motion picture format as in the cinema $\mathrm{CD}$.

Results: Prior to the demonstration of the product, we surveyed these schools on folksong preferences wherein girls expressed a much higher interest in folksongs over boys (Table 2 ). Reasons espoused were as follows: many girls claimed that they "liked the music better," they knew the songs, they could sing the songs, and/or that they liked the words. We observed that the ratings for folksongs were higher in schools further from the town. In terms of product impact on gender engagement, we found that the majority of girls in both private and government schools expressed preference for songs with the same language subtitling (SLS) over songs that did not provide this feature (Table 2). The prime reason expressed for the favoring of SLS was their desire to view the lyrics simultaneously as they could follow and enjoy the songs better. This corroborates with prior findings in the testing of the same language subtitling feature wherein audiences demonstrated preference for SLS as they saw it as a means to increase their enjoyment of these songs (Kothari \& Takeda, 2000). Few students, both boys and girls alluded to the literacy aspect of this feature when expressing their preference.

Furthermore, $96 \%$ of girls from the government schools and $92 \%$ of girls from the private schools claimed to enjoy the folk over the cinema CD-ROM. The reasons given for this varied based on the theme of the song. For example, in viewing Kantiki Katukapetti, the mother-daughter song, many girls claimed that they missed their parents as many of their parents worked in the field or were migrant workers (given this content was primarily about the bond between the mother and daughter in times of distress). Others stated that they liked the photographs, the music, and/or that it was easier to sing along as compared to some other songs. In fact, this song was reported as the top favorite among girls, $76 \%$ from the public schools and $69 \%$ from the private schools. Another interesting observation during this pilot project was the behavior and attitude of the boys towards these dominantly female-themed folksongs. During Jum Jum Taaraare (the solidarity song by SHG women) for example, several boys sang along with the 
lyrics with enthusiasm as they were familiar with this song. When asked on the reason for this familiarity, they reported that they often accompanied their mothers to SHG meetings and would hear these songs during that time. They expressed little inhibition in singing along with these songs ${ }^{\mathrm{vi}}$. Again, the religious song was very popular among both boys and girls, stated as a popular song at several local festivities in their communities and homes. However, the Urdu girls school served as the exception as the headmaster showed strong aversion to this Hindu religious song as the school constituted solely of Muslim children.

After the demonstration, we interviewed the teachers on their preferences. Most expressed a strong bias toward folk over film material, as they considered cinema content inappropriate and "immoral" in school settings. They espoused the integration of folk into their curriculum through moral science classes and cultural activities (Table 2). Again, much like the students, few teachers referenced literacy as a reason for usage of this content in their classrooms. There was less enthusiasm overall towards folk content among private school teachers and the principles. For example, one principle (who was from Dubai and had recently settled in Kuppam), in commenting on the usage of this content in the classrooms reported that it was useful to show it to these students as they could see how "their ancestry lived in the past". Part of this disconnect could be explained on the grounds that many of these principles and founders of private schools were not from the area, often coming from towns, other states and at times even different countries.

\section{DISCUSSION}

Given these results, we need to identify the features that have potential for positive outcomes on gender engagement for literacy and technology usage. In doing so, we can effectively modify, transform, and emphasize various aspects of this product so as to maximize engagement amongst girls in rural India.

\section{From bars to the classroom: karaoke for female solidarity}

In the case of this pilot project, the girls were able to enjoy a shared activity with shared technologies within the school setting contributing to a shared experience. Given the average ratio of ten students to one computer in rural villages in Kuppam constituency (KADA 2003), there is a need for multimedia products that serve group learning where educational, social and cultural practices can be integrated and harnessed meaningfully for social engagement. Thereby, one is able to take the disadvantaged aspect of limited resources and turn it into a positive force for solidarity and reinforcement of literacy through group engagement. The karaoke tool is one such means wherein interacting with this electronic communications technology becomes a cultural practice.

Lum (1996) advocates the karaoke experience as that which facilitates maintenance and (re)construction of social identity as communities interact with karaoke, (re)defining and shaping relationships with the medium as well as each other. The author professes that varied cultures and groups with different social frames of reference will react to this experience in divergent socially interactive ways and will imbue the semiotics of the text within their own cultural and social environments to produce socially shared meaning. In doing so, the author suggests that the karaoke audiences is not merely media text readers but rather are producers and consumers, functioning as active agents in localizing existing media in ways meaningful to them. This process the author argues can facilitate social bonding and community strengthening which can be particularly useful within economically deprived communities.

Originally, karaoke evolved from men's amateur social singing in bars in Japan in the 1970s where karaoke was used as a male space of socialization and entertainment. Today, through the localization and contextualization of songs, females are able to claim their cultural, social, regional and gendered differences and identities in karaoke spaces (Adams, 1996; Zheng, 1993). The public nature of karaoke interaction in particular lends itself well to socialization of groups and individuals. According to Adams (1996), karaoke is an experience of scripted simulation for groups. In other words, a set of multicultural and transnational mechanisms scripted by and for girls for example, and internalized by them through shared performance creates and reinforces their group identities.

\section{Girls accessing literacy through karaoke text}

In using karaoke, literacy skills are contingent amongst participants. The SLS folksongs product with its same language subtitling feature provides girls exposure to print in Roman and Telugu script in an entertaining and engaging format. In rural India for example, school textbooks are often the only print material available for a literacy hungry public (Stromquist 1990, 1992). By following the lyrics of the folksongs, the girls are compelled to read the lyrics as the song plays on. By singing along with the song, they are able to practice and build on their literacy skills on an ongoing basis. This product has been found to be more effective amongst neo-literates than non-literates as it helps sustain reading practices through continued exposure to print (Kothari, Pandey, \& Chudgar, 2004). According to Stromquist (1990), illiteracy can be viewed as a manifestation of an unequal distribution of power and resources in society. She argues that women, by most standard analysis of rates of return in education show benefits equal if not greater to that derived from men. Womens literacy is accordingly reflected in lower infant mortality, better health of children, higher levels of education for their children, and less children per household.

Furthermore, in combining text in the local language with computer interfacing, this tool has the potential to mitigate the literacy and digital divide at the same time. According to a recent study on gender and information technology in developing countries (Hafkin \& Taggart, 2001), the authors argue that some of the prime obstacles to access and usage of computers are the inadequate literacy and language skills of girls in developing countries. In fact, with 
girls literacy rates in India standing at $39.4 \%$ as of 2000 (p.11), they claim that education is perhaps the single most important factor in improving the ability of these girls to take full advantage of opportunities offered by information and communication technologies. Interestingly, new literacy discourses bring to question the very aspect of confining literacy to the text medium. Kress (2003) exemplifies this new perspective in his works by addressing how semiotics are structured by the interplay of text, image, color, music and other modes, each sharing in the (re)construction of meaning. This stands in contrast to conventional perceptions of text as an embodiment of meaning, thereby losing its privileged position in the hierarchy of knowledge production. Kress thereby challenges the very parameters within which literacies are construed:

Literacy is now not defined as the technology for transcribing sounds as letters, or as the technology for making graphic marks called letters combine into units called 'words'. Literacy can now be any system of transcription or recording, whether of sounds or of ideas. If it can be both the technology for transcribing sounds or for transcribing ideas, or mixtures of the two, then 'literacy' has come to mean 'transcription system' simply, and the decision for us to settle is then what it is we wish to transcribe and how, and with what resources, we wish to transcribe or record it . That system is then not (just) tied to language, but can extend to music, to numbers and to many other forms of 'expression'. (2003, pp. 27)

We can find roots of this new media studies in works of LeviStrauss (1966) when describing the 'bricolage' process to Fiske (1989) in his theory on producerly and writerly texts. Thereby, it is definitely worth of further investigation to tie new media studies to the interpretation and construction of content for high end technologies in rural India as we confront complex issues on culture and society. However, what can be said here is that the SLS folksongs product, in being viewed through this multimodal and multiliteracy lens can be said to embody multiple 'texts,' thereby stretching the potential for interpretation and democratic participation of meaning making.

\section{Gendered enculturation and empowerment through digitalized folk music}

This tool employed folksongs of interest to girls as a strategy to engage them in literacy and technology usage and practice. In utilizing folksongs for karaoke, this product was by default adopting a rich, dynamic and complex system of symbols and multiple layered meanings that embodied strategies in navigating, negotiating, and shaping rules and norms in society. For example, when expressing the estrangement of the daughter in a new household in the Kantiki Katukapetti song, the theme is braced through the mother-daughter relationship and appears to use symbols such as marigold flowers, kajol, the eye liner, and the like to indicate intimacy and empathy within the female context in rural India. For a deeper and elaborate understanding of the semiotic structures in folksongs that have agentic capacity, a much thorough discourse analysis of this content is needed. One can state however that folksongs have several metaphors inscribed within it, allowing perhaps for discretion and interpretation of messages by females that are not necessarily accessible to males. These need not be feminist messages but can serve the woman who is able to recognize these familiar signs as it pertains to her life and (re)interpret accordingly.

One of the most eloquent texts on this subject is, "Listen to the Heron's Words: Reimagining Gender and Kinship in North India" by Goodwin and Grodzins (1994). They thoughtfully analyze folksongs within the social life and customs of women in rural India revealing several commonly held misconceptions of women portrayed as passive, decorative, submissive, and subordinate; as entities within a patriarchal economy, ashamed of their sexuality; with religion and tradition systemically and historically devaluing them. Instead they make the case for women using poetry and metaphor through folksongs to resist structures of power, challenging at times dominant traditions at every turn. Also, rather than submissive vulnerable imagery, an ethnographic approach to folksongs in rural India exposed the vitality and positive force that emanated from contested representations and heterogeneity pervading across themes. Kuppam folksongs similarly display a wide range of stories and songs sung by women expressing genres depicting the most poignant experiences of girls and women's lives: leaving ones natal home and going off to the unknown house of a new husband (Kantaki Katukapetti), the hardship of losing all possessions and starting over again (Jum Jum Taaraare), the bounties of mother nature (Relare), walking the path of learning with education as "the third eye" (Chadavalira) and the like. Yet, despite the variation, several of these songs converge and intersect, and at times contradict within worlds of gender ecology, economy and other unconventional and conventional arenas for women. For example, all these songs weave in the environment, be it "the mother river from the hills and valleys," the source of life in the Relare song, raindrops becoming a river to indicate savings in the microfinance initiative as in the Jum Jum Taaraare song to education as the sky and its stars as in the Chadavalira song.

In terms of cinema versus folk music in India, Bollywood cinema has been functioning as a legitimate mass media metaphor for Indian society at large (Ahmed, 1992). According to Ahmed, the older generations of cinema heroes were distinctly indigenous, while the present heroes are more representative of outside western ideas and influences. The heroines previously symbolized the purity of the village while today's woman is shown to flaunt her assets. This the author claims has led to a widening gap between mass media and the rural folk media. It has been reflected in the composition of the songs where "the subdued songs of rural life have made way for boisterous urban chaos" (Ahmed, 1992). While I agree on the widening of gaps between mass media and folk, I do not subscribe to Ahmed's view of polarizing these domains on the lines of rural and urban for as Goodwin and Grodzins demonstrates in their book, folk music can be equally if not more raunchy, sexual and explicit in nature. We find evidence of this thinking in the work by Brandes (1980) where the author suggests that while it was considered at times daring for a woman to appropriate certain folk language that alluded to 
sexual issues for their own sexual expression, women continued to do so by negotiating their identities amongst their groups and developing strong competencies in using the language and deep knowledge of local ecologies and cultures to navigate and express on this subject. Interestingly, music in itself though has an ordered system of meanings and symbols in terms of which social interaction takes place (Lewis, 1982). Parallels have been drawn between music and social structure wherein music does not merely reflect the social structure but creates it. Music is therefore a framework of beliefs, expressive symbols and values in terms of which individuals define their world, express their feelings, and make their judgment. Further research needs to be done however on how the musical aspects of folk can transform literacy practices and meaning making among girls in rural India. Overall, as Foucault (1980) states, it is important to return to the local and forgotten knowledge, the subjugated knowledge that has been historically disqualified so as to discover underlying forces within the local fabric.

\section{Women as co-producers of media content}

By partnering with women folk artists, women groups and other community organizations and cultural groups, we were able to co-produce this content and allow for participation in media production by drawing on local issues and concerns. This has been a significant contributing factor for engagement as the girls and boys were familiar with the songs and were able to sing along with them. Also, in women participating in the production of their own content, they get to reposition their authority in society and become part of a local, national and/or global cultural flow. In analyzing media that is produced by marginalized groups, Ginsburg (1994) describes it as combining cultural ritual knowledge with MTV like effects. The underlying principle is similar to that of the SLS folksongs project wherein engagement, enculturation and empowerment are intended through the channels of folksongs for entertainment using film songs as a benchmark for quality of production. Langton (1993) argues that media producers are in essence "ritual managers" while others in front of the camera are "ritual owners." In other words, media makers are involved in production as a form of social action. For instance, the issue of visual and narrative form is not a primary concern for evaluating media. Quality is ascertained by the capacity to embody, sustain, revive or create certain social relations. Thereby, content produced is perceived as an extension of the marginalized group self-definition. Furthermore, the need for representation on national $\mathrm{TV}$ or other media sources of dissemination has a political dimension and direct effect on political culture (Michaels \& Kelly, 1984). Awareness on the connection between political enfranchisement and the need to control their own images in the media is fundamental in the production of such content. Questions still persist that are outside the scope of this paper but are critical nevertheless: How do indigenous media makers understand their own work? How do people understand the indigenous work as it spans across new arenas? What aesthetic standards are applied to these works? Are these ideas able to cross over cultural borders? How are notions of indigenous media negotiated in productions?

Furthermore, Ekstrand (1987) remarks that much of the developing countries have content that reinforce stereotypes of women due to their lack of involvement in the process of production. The author's analysis reveals that literacy content for women across economically poor regions reported emphasis on breastfeeding, kitchen work, gardening, immunization, sewing and home economics. Part of this stems from the local government literacy programs efforts at precluding women's participation in decisions on content creation and implementation. Thereby, allowing women's voices to enter mainstream media legitimizes not just their content, but rather the communities of situated practices that are interwoven within and around these cultural (re)productions.

\section{CONCLUSION}

In producing educational content for new technologies in novel and challenging settings, we have to recognize that enhancing literacy and documenting and disseminating social and cultural themes however noble an endeavor, is still very much part of the "development project" that is plagued with a historical baggage of misinterpretation, misappropriation and at times devaluation and disenfranchisement of the populace at the receiving end. Thereby, there is a thin line that differentiates these efforts from propaganda, benign as it may be. It is critical therefore to place meaningful engagement through co-production with the community at the forefront to mitigate the inevitable biases that seep into such projects. Further, in "empowering" girls, we cannot necessarily separate the "gendered" from the general folk content as that which interested the girls was not necessarily an overt feminist manifesto. Rather, these themes of female interest were intricately woven around complex matrices of the social, cultural, ecological and the economic that find its echoes in day to day communal and individual practices in rural India.

As to the usage of computers, this is by no means a channel to profound change in behavior of girl's usage of computers in rural India. Rather, it is a teasing out of new spaces for girls that can view this arena as that which is raw and moldable, a new variable in their fabric of existence. At this stage of the product, there is little genuine interfacing besides the karaoke entertainment component. Pending are features that will allow girls to interface with these songs, be able to pause this media and gain information on vocabulary, meaning, language translation, global perspectives through online search and offline exploration of populated resources, and other innovative means that can expand this product into a means for learning and critical thinking in schools in rural India based on situated practices. However, that is contingent on several external factors such as connectivity, hardware resources, school practices and the like.

There are some significant challenges in the dissemination of this multimedia tool across contexts. Budgets are often limited and small for global scaling which leaves folk 
media largely invisible and economically fragile. Furthermore, transference can be formidable as narrative contexts may not be represented abstractly enough to adapt and transfer to new contexts. Fisch (2002) states that for successful transfer to occur, there needs to be a rich understanding of the subject matter portrayed, an abstraction of the content beyond its original context and a linkage between the presented symbols and the new situation to which it needs to be applied. He suggests that the optimal solution may lie in presenting the same educational content in several different narrative contexts instead. The other issue of concern is misappropriation of context and cultures. The SLS folksongs product despite the involvement of the community in its production is still not free from the biases of the production team. The team still made several key decisions on the selection of folksingers, editing of folksongs, recording and the visualization of this product. These issues will continue to persist as long as development projects exist. However, we can strive to mitigate these effects through genuine involvement with the "other," harnessing their active voices and enhancing their self-efficacy in their own representation to symbolic narratives.

Acknowledgements: The production of the SLS folksongs project has been a team effort. I would like to thank Planetread's team: P.S Jayamma, Amit Dixit, Maya Sukumar, Nirav Shah, K.T. Pauly, and Ashok Joshi. We wish to thank Hewlett-Packard for funding and supporting this project. I am particularly grateful to the founder of PlanetRead, Dr. Brij Kothari for his mentorship in this process. I would like to pay tribute to the local Kuppam government office that provided access to Kuppam education and development data and to the Kuppam community at large for being tremendously helpful and inspirational in this project. Last, but not least, I would like to emphasize P.S Jayamma's invaluable role in this project. Due to her drive, local credibility and dedication, we were able to take this project to a much higher footing. Her efforts in this project have been deeply felt.

Table 2: Pilot Test of Folksong \& Cinema CD-ROM with SLS in Private \& Public High Schools-Kuppam, 2004

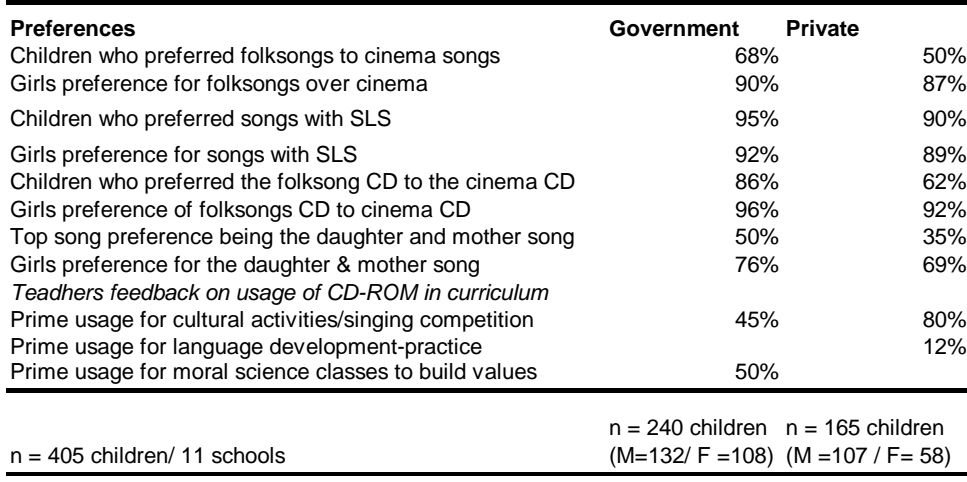

\section{REFERENCES}

Arora, P. (2006a). Karaoke for social and cultural change: Analysis of educational technology content production in rural India. Information, Communication and Ethics in Society, (in press).

Arora, P. (2006b). The ICT Laboratory: An analysis of computers in schools in India. Association of Advancement in Computing in Education Journal, (in press).

Adams, V. (1996). Karaoke as modern Lhasa, Tibet: Western encounters with cultural politics. Cultural Anthropology, 11(4), 510-546.

Ahmed (1992). Bombay films: The cinema as metaphor for Indian society and politics. Modern Asian Studies. 26(2).

Bernstein, J.(2000). It and the new economy: Macro, jobs, and gender. Washington DC: Economic Policy Institute.

Bhabha, H. (1990). The other question: Difference, discrimination, and the discourse of colonialism. In R. Table 1: Education and Gender statistics (Kuppam Area Development Authority 2003) Public Private

Total Enrollment of students in high school

High Schools founded within last 5 years

Female students in high schools

Students from Backward Castes, Scheduled and Tribal Castes

Female teachers in schools

Schools with girls toilets
$97.5 \%$

$70 \%$

$43 \%$

$90 \%$

$26 \%$

$32 \%$

Ferguson et al. (Eds.), Out there: Marginalization and contemporary cultures, (pp. 185-216): Oxford: Clarendon ${ }_{33 \%}^{33 \%}$ Press.

$60 \%$ Cockburn, C. (1992). The circuit of technology: Gender $76 \%$ identity and power. In R. Silverstone, \& E.Hirsch (Eds.), 49\% Consuming technologies: Media and information in domestic spaces ( pp. 33-42). London: Routledge.

Ekstrand (1987). Policy and practice of adult education for women in India. Paper presented at sixth world congress of Comparative Education: Rio de Janeiro.

Escobar, A.(1995). Encountering development: The making and unmaking of the Third World. Princeton: Princeton University Press. 
Fisch, M.S. (2002). Vast wasteland or vast opportunity? Effects of educational television on children's academic knowledge, skills, and attitudes. In J, Bryant, \& D, Zillmann's (Eds.) Media Effects. Second Edition, (pp.397-427), Erlbaum.

Fiske, J. (1989). Understanding popular culture. Boston: Unwin Hyman.

Foucault (1980). Power/Knowledge: Selected interviews and other writings. Trans. C. Gordon. New York: Pantheon Books.

Gehring, J. (2001). Technology counts 2001: Not enough girls. Education Week, 20(35), 18-19.

Ginsburg, F. (1991). Indigenous media: Faustian contract or global village? In Cultural Anthropology, 6(1), 92-112.

Ginsburg, F. (1994). Embedded aesthetics: Creating a discursive space for indigenous media. Cultural Anthropology, 9(3), 365-382.

Goodwin, G, \& Grodzins, A. (1994). Listen to the heron's words: Reimagining gender and kinship in North India. Berkeley University Press.

Hafkin, N, \& Taggart, N. (2001). Gender, information technology, and developing countries: An analytic study. Academy for Educational Development (AED)/ USAID. (No. HNE-1-00-96-00018-00, and Task Order 2432-21.)

Harris, R.J. (1999). A Cognitive Psychology of Mass Communication. New Jersey, Lawrence Erlbaum Associates, Inc.

Jenson, J., de Castell, S., \& Bryson, M. (2003). Girl talk: Gender equity, and identity discourses in a school-based computer culture. Women's Studies International Forum, 26(6), 561-573.

Klenk, R. (2004). Who is a developed woman? Woman as a category of development discourse, Kumaon, India. Development and Change, 35(1), 57-78.

Kothari, B., Pandey, A., \& Chudgar, A. (2004). Reading out of the idiot box: Same language subtitling on television in India. International Technologies and International Development, 1(3), 23-44.

Kothari, B., \& Takeda, J. (2000). Same language subtitling for literacy: Small change for colossal gains. In S. Bhatnagar., \& R. Schware (Eds.) Information and Communication Technology in Development (pp 176 - 186).World Bank Institute, New Delhi: Sage Publications.

Kothari, B. (2000). Same language subtitling on Indian television: Harnessing the power of popular culture for literacy. In K. Wilkins (Ed.), Redeveloping communication for social change: Theory, practice and power (pp 135-146). New York: Rowman \& Littlefield.

Kuppam Area Development Authority (2003). Statistics on education and development in Kuppam: Government of Andhra Pradesh. South India.

Langton, M. (1993). Well, I heard it on the radio and saw it on the television. Sydney: Australian Film Commission.

Levi-Strauss, C. (1966). The savage mind. Chicago: University of Chicago Press.

Lewis, H.,G. (1982). Popular music: Symbolic resource and transformer of meaning in society. International Review of the Aesthetics and Sociology of Music, 13(2),183-189.

Lum, C.M.K. (1996). In search of a voice: Karaoke and construction of a voice in Chinese America. Erlbaum.

Manuel, Peter.(1998). Music, identity, and images of India in the Indo-Caribbean diaspora, Asian Music, Vol. 29, No. 1. pp. 17-35.

Michaels, E, \& Kelly, J, F. (1984). The social organization of the Aboriginal video workplace. Australian Aboriginal Studies. 1, 26-34

Mohanty, C.T. (1991). Cartographies of struggle: Third world women and the politics of feminism. In C.T. Mohanty, A. Russo, and L. Torres (Eds.) Third world women and the politics of feminism, (pp.1-47), Bloomington, IN: Indiana University Press.

Parpart, J.L. (1995). Deconstructing the development 'expert'. In M.H. Marchand, and J.L. Parpart (Eds.), Feminism, postmodernism, development (pp. 221-243). London and New York: Routledge.

Schrum, L., \& Bracey, B. (2003). Gender issues and considerations. In G. Solomon, N.J. Allen, and P. Resta, Toward digital equity: bridging the divide in education, (pp115-129). Pearson Education Group, Inc.

Srinivasan, S. (2001). India's Silicon Valley. Retrieved April 1, 2006, from CNEWS Web site: www.argonauts.on.ca/CNEWSTechNews0110/29 indiaap.html

Stromquist, P.N. (1990).Women and illiteracy: The interplay of gender subordination and poverty. Comparative Education Review, 34(1), 95-111.

Stromquist, P.N. (1992). Women and literacy: Promises and constraints. Annals of the American Academy of Political and Social Science, 520, 54-65. 
Wajcman, Judy (1991). Feminism confronts technology. University Park, PA: The Pennsylvania State University Press.

Zheng, S. (1993). Immigrant music and transnational discourse: Chinese American music culture in New York City. Unpublished doctoral dissertation, Wesleyan University, Middletown, CT.

\section{ABBREVIATIONS}

AIDS Acquired Immune Deficiency Syndrome

DD Doordharshan

ICT Information and Communication Technologies

IIM-A Indian Institute of Management -Ahmedabad

KADA Kuppam Area Development Authority

HIV Human Immunodeficiency Virus

HP Hewlett Packard

NGO Non Governmental Organization

PC Personal Computer

PWG Peoples War Group

SHG Self Help Groups

SLS Same Language Subtitling

\section{NOTES}

iTech Laureate in Education (2003), Tech Museum of Innovations, San Jose, CA., Oct. 2003

ii See PlanetRead Inc.

:http://www.planetread.com/files/html_files/folksong_files/folk song.htm

\footnotetext{
iii See details on the Inclusive Community project on the Hewlett Packard web http://www.hp.com/hpinfo/globalcitizenship/gcreport/socialinvest/einclusion. $\underline{\mathrm{html}}$

iv The Same Language Subtitling feature won the World Bank Development Market Place Award in 2002: http://web.worldbank.org/WBSITE/EXTERNAL/OPPORTUNITIES/GRANT S/DEVMARKETPLACE/0,,contentMDK:20100393 menuPK:214469 page PK:180691 piPK:174492 theSitePK:205098,00.html
}

" The Vidya Vahini Scheme, an Indian government initiative (2000) is meant to deploy computers across high schools in India, connecting 60,000 school going children in the next five years. www.mait.com This scheme was launched in Kuppam under the leadership of Chandrababu Naidu, the former chief minister of Andhra Pradesh, India. For further information, see Arora, 2006b.

vi Although I focus on the impact of this product on girls' engagement in Kuppam, I believe it is important to address the attitudes and behavior of boys in alluding to gender empowerment. Unfortunately for now it is beyond the scope of this paper. 